\title{
El glosario escondido en El arte culinario (1900) de Adolfo Solichón
}

\section{The hidden glossary of Adolfo Solichón's El arte culinario (1900)}

\author{
ELENA CARPI \\ elena.carpi@unipi.it \\ Università degli Studi di Pisa \\ Matteo De Beni \\ matteo.debeni@univr.it \\ Università degli Studi di Verona
}

\begin{abstract}
Resumen: El presente artículo analiza el «Vocabulario de varios términos culinarios» incluido en El arte culinario (Madrid, Romo y Füssel, 1900) del cocinero y gastrónomo Adolfo Solichón, «discípulo de Casa Lhardy». Tras describir el contexto de la época en que la obra fue realizada, proporcionar algunos datos de interés sobre el autor y la gastronomía de las postrimerías del siglo XIX y detallar los principales aspectos paratextuales del glosario, se analiza el léxico del «vocabulario escondido» objeto de estudio, atendiendo a su macroestructura. Más en concreto, se pone el foco en la incorporación de formaciones neológicas, lexías compuestas y galicismos.
\end{abstract}

Palabras clave: glosarios escondidos; léxico gastronómico; Adolfo Solichón; galicismos.

Abstract: This article analyses the «Vocabulario de varios términos culinarios» included in El arte culinario (Madrid, Romo y Füssel, 1900), written by the chef and gourmet Adolfo Solichón, «disciple of Casa Lhardy». After exploring the historical context and describing some author's biographical data, some aspects related to the gastronomy of the late nineteenth century and also the main paratextual features of the glossary, the lexicon of Solichon's «hidden vocabulary» is analysed considering its macrostructure. More specifically, the analysis focuses on the inclusion of neologisms, compounds, and Gallicisms.

Keywords: hidden glossaries; gastronomic lexicon; Adolfo Solichón; Gallicisms.

\footnotetext{
* Este trabajo se enmarca en las actividades del grupo de investigación Diccionarística del siglo XVIII (DICCIOCHO; coords. Elena Carpi y Francisco M. Carriscondo Esquivel) y del grupo de investigación El léxico del español en su bistoria (LEHist, coord. Matteo De Beni). Aunque el artículo ha sido elaborado conjuntamente, a efectos académicos Matteo De Beni es responsable de los apartados 1., 2. y 3.; Elena Carpi de los apartados 3.1., 3.2., 3.3. y 4.
} 


\section{Introducción}

En el año 1900 sale de la imprenta de la editorial Romo y Füssel de Madrid un enjundioso volumen titulado El arte culinario, un manual de cocina firmado por Adolfo Solichón. Las casi 500 páginas del tratado las ocupa sobre todo su amplio recetario, vertebrado en secciones que reúnen los platos o alimentos según su tipología y que siguen, además, en su mayoría, el orden de presentación en la mesa sobre la que el propio autor instruye a su lector al comienzo del manual:

Orden por el cual deben presentarse los platos:

Las sopas.

Los platos volantes fríos (salchichón, aceitunas, etc.).

Los platos volantes de cocina, calientes.

Los relevés de pescado.

Los relevés de carnes.

Las entradas de vaca, ternera, ave ó caza.

Las entradas frías.

El ponche á la romana. (El ponche se sirve siempre entre las entradas frías y las legumbres.)

Las legumbres.

Los asados de ave ó caza.

Las ensaladas.

Los dulces de cocina calientes.

Los dulces de cocina fríos.

Los helados.

$[\ldots]$

Los quesos, las frutas, los dulces de repostería y bombones.

El café y licores se sirven en el salón.

(Solichón 1900: 16) ${ }^{1}$

Como se desprende de la amplia y variada nómina de platos, el de Solichón es un tratado que propone al alcance del público una cocina para gente acomodada. Lejos de ser un prontuario con consejos dirigidos al ama de casa para el aprovechamiento de las sobras o para una «cocina de necesidad», esto es, de subsistencia, es, al contrario, un libro de gastronomía que presenta la comida como un acto social. ${ }^{2}$ De ahí que el volumen no abarque solo el recetario, sino también algunos apartados que subrayan la importancia de la obra y su índole sofisticada. En primer lugar,

1 En todas las citas mantenemos la ortografía y la acentuación originales.

2 No es así en el caso de otros manuales decimonónicos, que en algún caso anuncian desde sus propias portadas la actitud contraria: véase, por ejemplo, La gran economía de las familias. Arte de arreglar y componer lo sobrante de las comidas de un día para otro, dedicado á las clases menos acomodadas, y gentes de poco dinero, que gusten de comer bien, gastar poco y no desperdiciar nada (1869), cuyo autor anónimo se firma con el pseudónimo de "Un gastrónomo jubilado". También Ángel Muro (18911894), autor que se mencionará varias veces a lo largo del presente trabajo, indica en el título de su tratado culinario que es útil para el «aprovechamiento de sobras». 
incluye tres elementos paratextuales: un prólogo firmado por el propio autor, una breve carta a Solichón de Agustín Lhardy —en que el dueño del conocido restaurante madrileño manifiesta su bienestar respecto a nuestro manual - y otra premisa en alabanza de la obra por Francisco Capella, «Ex cocinero del Real Palacio» (Capella 1900: 12, cursiva en el texto). En segundo lugar, aparece una sección dedicada al «Servicio de mesa» y, por último, también un «Vocabulario de varios términos culinarios». Precisamente las páginas consagradas al «Servicio de mesa» muestran la importancia que Solichón otorga a la etiqueta y a las costumbres que convierten un convite en un evento refinado y elegante, de buena sociedad, como se infiere de los títulos de los distintos apartados de la sección en cuestión: «Ornamento de las mesas. Disposición de los cubiertos. Servicio»; «Orden por el cual deben presentarse los platos»; «Orden por el cual deben presentarse los vinos»; «Deberes del anfitrión y de los convidados».

El carácter instructivo de la obra, de todos modos, rebasa los límites del decoro social y de los buenos modales para alcanzar la lengua, más en concreto, el conocimiento de los términos culinarios. Por ello, como hemos dicho, Solichón incluye en su obra un vocabulario. ${ }^{3}$

El objetivo del presente trabajo es precisamente el de examinar dicho repertorio léxico. En primer lugar, ofreceremos un acercamiento al contexto dentro del cual se originó la obra de Solichón —y, por ende, el propio «Vocabulario de varios términos culinarios»—; luego, analizaremos el paratexto que introduce el repertorio y la macroestructura del vocabulario, haciendo hincapié en algunos aspectos destacados: las formaciones neológicas — tanto nominales como verbales-, el registro de lexías compuestas y la incorporación de galicismos, que se presentan de manera transversal con respecto a las demás tipologías léxicas estudiadas. ${ }^{4}$

Para contrastar la aportación terminológica del glosario de Solichón en cuanto al léxico de la cocina y la gastronomía de la época, hemos considerado como corpus de control el Corpus del Diccionario Histórico $(C D H)$ de la Real Academia Española y, además, dos diccionarios de especialidad: el Diccionario General de Cocina, de 1892, de Ángel Muro - un autor que tuvo un papel protagónico en el ámbito culinario de la época - y el Pequeño Diccionario Ilustrado de los términos usuales en la cocina, publicado en el año 1900 por José de Praussols. En cambio, para averiguar la incorporación de las voces culinarias propuestas por Solichón en los diccionarios de la lengua general hemos empleado el Nuevo tesoro lexicográfico de la lengua española (NTLLE). ${ }^{5}$ Los datos cuantitativos que mostraremos se han obtenido con el programa SketchEngine.

3 El interés por el léxico culinario se desprende, además, de otros elementos a lo largo de la obra. Por ejemplo, hacia el final del volumen, Solichón incluye un índice analítico que titula «Tabla alfabética de todas las formulas contenidas en esta obra y de algunos términos culinarios empleados en la misma» (1900: 471, cursiva nuestra).

4 En cambio, en esta ocasión no nos ocupamos de la microestructura del vocabulario, a la que dedicaremos otro trabajo futuro. Este último ofrecerá también la oportunidad para ahondar en las relaciones entre el léxico culinario propuesto por Solichón en su vocabulario y el empleado en materiales auténticos del ámbito de la gastronomía de la misma época.

5 Los diccionarios consultados en el NTLLE se citan por la sigla RAE o, en el caso de obras no académicas, por el apellido del lexicógrafo y el año correspondiente. 
El trabajo que presentamos se enmarca en los estudios sobre los glosarios escondidos, como se ha dado en denominar en la metalexicografía a este tipo de recopilaciones incorporadas a una obra de mayor extensión. ${ }^{6}$ Se trata de un terrero fructífero en los estudios lexicográficos actuales, que no han olvidado el ámbito gastronómico: por ejemplo, en un trabajo reciente, Torres Martínez (2018) estudia el glosario escondido de una obra de envergadura dentro de la culinaria de las postrimerías del siglo XIX, es decir, El Practicón. Tratado completo de cocina, de 1894, firmado por el ya mencionado Ángel Muro.

\section{E1 arte culinario y su contexto}

La portada del tratado de Solichón sugiere de por sí elementos suficientes para dilucidar de manera sintética el contexto en que la obra se produce. Empezamos por los aspectos relacionados con la gestación y edición del tratado. En primer lugar, a través del subtítulo, la obra se presenta como un «tratado práctico y completo». Ahora bien, de esta índole práctica del manual de Solichón se encuentran ecos en los prólogos que encabezan la obra: el del propio Solichón y el firmado por Francisco Capella. Este último afirma que la mayoría de los libros de cocina son inútiles, ya que «están llenos de vaguedades y deficiencias imposibles de subsanar en la práctica» y «abusan de la teoria» o bien, al contrario, «creen que lo que hay que enseñar es cocina económica, cocina casera» (1900: 10). En cambio, de estos defectos está exento, según Capella, el manual de Solichón. Además, lo práctico y lo útil son conceptos bien presentes, como veremos, en el conjunto de la obra. Asimismo, en la portada se afirma que es una «Obra ilustrada con profusión de dibujos intercalados en el texto». Aunque no entramos en detalles en cuanto al aparato iconográfico de la obra se refiere, merece la pena destacar que, al lado de orlas y de otras imágenes que sirven de adorno, también se incorpora al texto una serie de 66 figuras - algunas insertadas en el glosario y otras en el textonumeradas y acompañadas por un pie de imagen: se trata, casi siempre, de representaciones de enseres culinarios (53 casos) y de pescados (11 casos). De ello se infiere el propósito instructivo de dichas ilustraciones: de hecho, sirven para sufragar al lector en la identificación de los significantes con sus significados en los casos más complejos y potencialmente dudosos: precisamente, los utensilios, por un lado, y los pescados, por el otro (sobra destacar aquí lo enmarañada que llega a ser en español la variación diatópica de la ictionimia).

En cuanto a los editores del tratado, cabe señalar que el establecimiento de Romo y Füssel, en los inicios del siglo XX, se dedicó precisamente a la publicación de tratados prácticos, come el de

6 Los glosarios escondidos se encuentran en manuales y tratados de distintas disciplinas, sobre todo científicas y técnicas, entre muchas otras, la minería (Díez de Revenga 2008), la medicina (Gutiérrez Rodilla/García Jáuregui 2012), la agricultura (Pinilla/Lépinette 2012) y la tipografía (Pablo Núñez/De Beni 2019). En cuanto a la definición de glosario escondido, la propia Díez de Revenga apunta que se trata de una «denominación que forma parte de la terminología metalexicográfica desde mitad del siglo XX para designar los glosarios de voces científico-técnicas que contienen determinados tratados técnicos [...]» (2008: 655-656). 
Solichón, y pertenecientes a distintos ámbitos. ${ }^{7}$ Asimismo, es interesante el hecho de que hubo por lo menos otras dos ediciones del tratado, en 1906 y en 1913, lo cual sugiere que la obra siguió despertando cierto interés. ${ }^{8}$

La portada también refiere aspectos relacionados con el contexto cultural y gastronómico. Primero, se reivindica el linaje de Solichón como cocinero, en cuanto «discípulo de Casa Lhardy»—el famoso restaurante de Madrid - y «exrepostero de SS. MM. los Reyes de España». ${ }^{9}$ A esta tradición de alta cocina corresponden los aspectos relacionados con la comida como acto social, que también se anuncian en la portada como parte de los contenidos de la obra, rasgo que ya hemos señalado supra. Por último, cabe destacar que Solichón afirma seguir la «Escuela moderna francesa y española», esto es, dos tradiciones al mismo tiempo. Es cierto, como veremos, que en su manual la influencia gala es acusada, pero, al mismo tiempo, el autor no desestima la cocina española, incluso la regional, como sugieren algunas de las recetas incluidas en su obra. Parece, así pues, proponer su tratado como un compendio de las dos escuelas.

Es evidente que, al ser discípulo de casa Lhardy — cuya ascendencia francesa es notoria—, Solichón no puede pasar por alto la potente corriente culinaria del país vecino. Al mismo tiempo, cabe destacar que, en España, representantes de generaciones distintas de gastrónomos y cocineros promovieron la tradición culinaria española para apuntalarla contra el avasallador influjo francés, lo cual suponía también matizar, hasta cierto punto, la influencia lingüística de los galicismos en el ámbito en cuestión. ${ }^{10}$

7 El catálogo de la Biblioteca Nacional de España consigna ocho registros, entre 1900 y 1903, relacionados con la serie Manuales Romo y Füssel.

8Se trata de las siguientes ediciones: Madrid, Adrián Romo, 1906, 2.a ed. aumentada; Madrid, Imprenta Española, 1913, 3.a ed. aumentada. Nuestro trabajo se basa, de todos modos, en la primera edición (1900). Martínez Llopis (1998: 368) señala que El arte culinario fue editado en Madrid en 1923; desconocemos si se trata de un error o si, en cambio, este autor reseña una reedición o reimpresión tardía. Además, la obra parece haber tenido por lo menos una reimpresión en el año 1902, dado que el libro se anuncia en la sección «Libros nuevos» del diario coruñés El Noroeste el 26 de mayo de 1902: «El tratado de cocina del Sr Solichón publicado por la acreditada casa editorial de Romo y Füssel merece por más de un concepto la atención de los aficionados al arte de Brillat-Savarin [...]. Un vocabulario de términos de cocina completa esta útil obra, ilustrada con buenos grabados y correctamente impresa» (Biblioteca Virtual de Prensa Histórica). Señalamos que, curiosamente, el propio director de El Noroeste, Manuel Puga y Parga, publicó en 1906 en La Coruña su propio tratado de cocina, con recetas «casi todas de la más pura y tradicional cocina hispánica, en especial de la región galaica» (Martínez Llopis 1998: 354).

9De Adolfo Solichón no tenemos a disposición muchos más datos biográficos. Sin duda, pudo aprovechar su experiencia en Casa Lhardy, como quizás también sugiere el hecho de que su obra sea un «tratado completo», que incluye — como anuncia la portada - «Cocina, pastelería y repostería»: esto es coherente con la tradición de Casa Lhardy, que nació como pastelería para llegar luego a la restauración. Otro aspecto que, gracias a la Hemeroteca Digital de la Biblioteca Nacional de España, hemos podido averiguar es que, entre 1906 y 1915, algunas recetas de El arte culinario fueron nuevamente publicadas, a menudo con leves retoques formales, en la prestigiosa revista gastronómica El Gorro Blanco, editada desde 1906 hasta 1946.

10Según un documento recogido por Martínez Llopis (1998: 345-346), en la segunda mitad del siglo XIX la influencia francesa era tan evidente que las minutas (menús) de las comidas del Palacio Real se redactaban habitualmente en francés. 
Entre las figuras de esta sensibilidad «prohispana», recordamos de paso a Mariano Pardo de Figueroa (1828-1918), más conocido con el seudónimo de Doctor Thebussem, o al más tardío Teodoro Bardají (1882-1958). La existencia de sensibilidades culinarias distintas y la adscripción a escuelas diferentes puede explicar por qué el prologuista de El arte culinario y excocinero del Real Palacio, Francisco Capella, haga comentarios cáusticos en contra del ya recordado Ángel Muro, que había muerto en 1897, es decir, unos años antes de la publicación de nuestro tratado:

Ahí (en el limbo) está Ángel Muro, que no me dejará mentir.

Dios le haya perdonado al pobre los muchos desatinos culinarios que escribió en vida, en gracia al estilo ameno y á la erudición que derrochó en sus libros. (Capella 1900: 11)

\section{E1 «Vocabulario de varios términos culinarios»: paratexto y macroestructura}

El vocabulario de Solichón va precedido por una breve premisa, que hace hincapié en la necesidad de conocer y saber usar correctamente los tecnicismos gastronómicos:

Es sumamente necesario estudiar el nombre técnico de los utensilios y términos culinarios, así como conocer el uso que se les da, aunque algunos de éstos sean tomados del francés. Á continuación expongo una ligera explicación que creo ha de ser de mucha utilidad (1900: 21, cursivas nuestras).

En el uso del verbo estudiar y del concesivo aunque, que alude a la añeja y nunca resuelta cuestión de la incorporación de los galicismos al español, se aprecia la importancia que el autor otorga al correcto manejo del léxico culinario: para que la gastronomía española pueda seguir «el camino del progreso» (Solichón 1900: 5), el autor considera necesaria la introducción en el idioma de esta tipología de galicismos, ya que la importancia de la escuela francesa de cocina de entre siglos está fuera de discusión.

También a la hora de concluir su vocabulario Solichón incluye un breve texto en el que insiste en la preeminencia de lo útil, aspecto que — merece la pena recordarlo— ya hemos visto puesto en evidencia en la portada. De ahí que su glosario, más bien que por parámetros lexicográficos, se rija por el criterio de la utilidad. De hecho, el autor aclara que ha excluido de su recopilación los términos más conocidos y que dará más detalles sobre los objetos propios de su oficio a lo largo del tratado:

Respecto al vocabulario de objetos y términos culinarios, podría dar una explicación larguísima. Prefiero, pues, aparte de las indicaciones que acabo de exponer, ir haciéndolo, tanto respecto á los enseres como á los términos, según venga á caso en el curso de esta obra, pues muchos de ellos son también tan conocidos, que creo inútil detallarlos. (1900: 33).

En ningún caso, por lo tanto, Solichón pretende ser exhaustivo, como sugiere quizás ya el adjetivo varios insertado en el título que encabeza su glosario («Vocabulario de varios términos culinarios»). 
En cuanto a la macroestructura del vocabulario, sus 36 entradas siguen el orden alfabético, aunque la lematización no es rigurosa: en efecto, si bien todos los verbos están al infinitivo, no todos los sustantivos aparecen en singular, puesto que se encuentran los plurales boquillas, cucharas, espátulas, pinceles y varillas. Hay entradas dobles, como la compuesta por liar y trabar, divididos por una coma, y la que se desdobla en tamil ó cedaro; el vocabulario acoge también lexías compuestas como cacerola rusa, plato de saltear, manojo de hierbas aromáticas, cazo de cobre y fondos de cocina.

Otro aspecto relevante es que doce de las entradas del vocabulario están acompañadas por figuras: se trata siempre de imágenes de instrumentos de trabajo que ejemplifican lo que expone el artículo lexicográfico y le dan mayor claridad, como en el caso de la entrada cucharas, que no designa a la pieza de cubertería sino a un particular utensilio de cocina. Cada dibujo, así pues, tiene el propósito de ilustrar el lema al que se refiere, aunque a veces su pie de imagen introduce alguna variación con respecto a la forma lematizada, como en el caso de manga, cuya imagen correspondiente se denomina por ampliación «manga de dril». En el caso de la voz corta-pasta el dibujo se refiere en realidad a «cajas de corta-pastas», mencionadas en la definición (fig. 1).
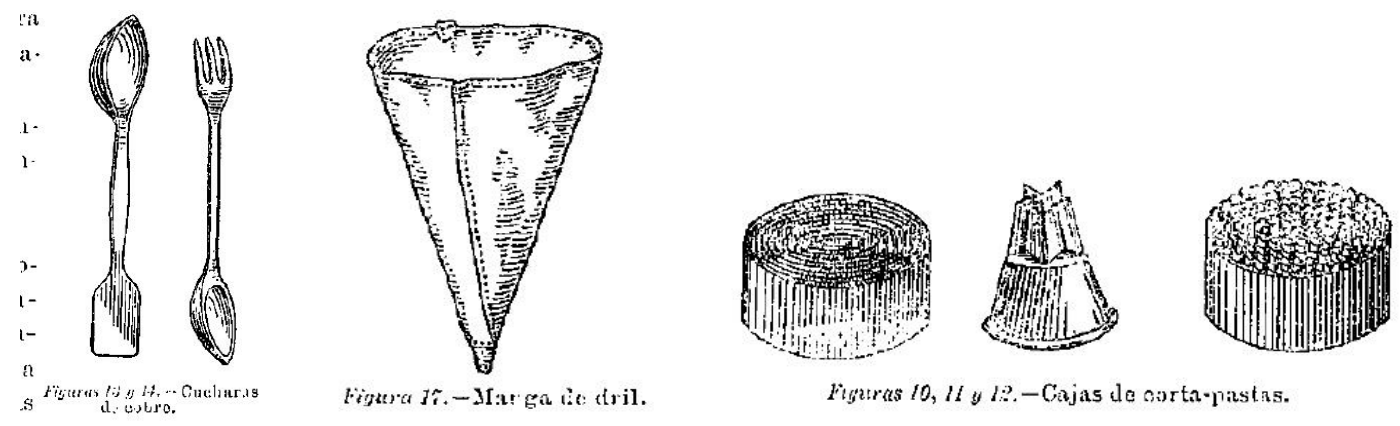

Figura 1. Muestras de imágenes del glosario.

Puesto que el «Vocabulario de varios términos culinarios» no es muy extenso, nuestra hipótesis de partida fue que el autor privilegiara palabras poco conocidas y que necesitaran explicación (dado que él mismo afirma que prescinde de las más comunes, como hemos visto), además de voces usadas con frecuencia en su propio tratado: sin embargo, los datos que presentamos en los apartados que siguen evidencian una situación más compleja.

\subsection{Sustantivos}

La tabla 1 reúne los sustantivos presentes en el vocabulario, conservando su forma y ortografía; como mostramos en la segunda columna, las voces van ordenadas según el número de sus ocurrencias en el texto, sin considerar las del índice. Por último, señalamos con un asterisco las formas neológicas o cuyo testimonio está muy cercano a la fecha de publicación de El arte culinario: 


\begin{tabular}{lll|}
\hline Sustantivos & Ocurrencias & Formas neológicas \\
\hline & & \\
cedazo & 133 & \\
cocimiento & 99 & $*$ \\
espátulas & 38 & \\
estameña & 33 & $*$ \\
varillas & 21 & $*$ \\
corta-pastas & 19 & $*$ \\
pinceles & 13 & $*$ \\
manga & 12 & \\
tamiz & 10 & $*$ \\
baño-maría & 8 & $*$ \\
boquillas & 8 & \\
perol & 7 & $*$ \\
cucharas & 6 & $*$ \\
tambor & 3 & $*$ \\
bresera & 2 & $*$ \\
cuerna & 0 & $*$ \\
espolvoreadera & 0 & $*$ \\
pasa-caldos & 0 & \\
pinzas & 0 & \\
& &
\end{tabular}

Tabla 1. Los sustantivos y su frecuencia de uso en el tratado.

Hemos apuntado que se trata de una situación compleja, puesto que la mayoría de los 19 sustantivos son palabras que se encuentran solo en Solichón o que, en la época de publicación de nuestro texto, tienen una formación muy reciente. Por consiguiente, su inclusión en el tratado se podría justificar con la necesidad de proporcionar una explicación de dichas voces; sin embargo, su frecuencia de aparición en el propio texto es muy baja, e incluso hay palabras que el autor no utiliza nunca. En cambio, aunque los demás sustantivos pertenezcan al idioma español desde hace siglos y su sentido sea transparente, se encuentran incluidos en el vocabulario.

La influencia francesa en la terminología presentada es muy acusada y, como vamos a mostrar, puede crear incongruencias entre El arte culinario y su glosario: por ejemplo, para sustituir la palabra francesa glacière, Solichón propone espolvoreadera; sin embargo, subraya que el nombre francés es más usado, y de hecho en el tratado la forma española no se encuentra en ninguna ocasión. 
Baño-maria, la traducción castellana del francés bain-marie, se registra en Muro (1892) y Praussols (1900) con el significado de 'cacerola', que también le atribuye Solichón en su vocabulario. En cambio, en el texto el autor no usa la palabra como instrumento, sino como método de cocción, como muestran las unidades fraseológicas poner al baño-maría, calentar al baño-maría, escalfar al bañomaría, cocer al baño-maría, etc.

La voz bresera podría ser la adaptación castellana del francés braisière, formada del verbo braiser, así descrita en el Trésor de la Langue Française: «Faire cuire un aliment (bœuf, laitue, etc.) sur de la braise, p. ext. à feu doux et à couvert» (s.v. braiser). Solichón afirma que «su verdadero nombre debiera ser: Braseadora, pues se deriva de brasas; pero, ya digo, se le llama bresera» y el propio autor utiliza la palabra braseadora en el artículo brasear.

El neologismo de sentido espátulas, probablemente inducido por el francés spatule, llega a la gastronomía desde la botánica y la medicina: según el $C D H$, antes de El arte culinario se encuentra en una obra sobre repostería de autor anónimo (1822a), en Muro (1892) y en Praussols (1900). Sin embargo, las obras lexicográficas anteriores a nuestro tratado reunidas en el NTLLE no documentan el uso culinario de la voz. Otros neologismos de sentido son cucharas, varillas, boquillas, tambor, manga, cuerna y pasa-caldo, de los que no hay rastro, con el significado que les da Solichón, en los diccionarios consultados ni, hasta la fecha, en el $C D H$.

El término más recurrente es cedazo, que forma parte de la entrada tamiz ó cedazo, palabras que pertenecen al idioma español respectivamente desde los siglos XVIII y XVII: la primera es un galicismo que se testimonia lexicográficamente desde RAE 1739, mientras que la segunda es un latinismo que se encuentra ya en Covarrubias (1611). Además, la consulta del CDH informa que, desde la primera aparición de las dos voces en 1529 en el Libro de guisados de Ruperto de Nola y hasta la publicación de El Practicón. Tratado completo de cocina (1891-1894) de Ángel Muro —un hito de la gastronomía española-, en los textos de gastronomía se utiliza mayoritariamente tamiz respecto a cedazo. En el corte temporal siguiente, el de la primera mitad del siglo XX, cedazo tiende incluso a desaparecer como voz culinaria (figura 2). La inclusión en el vocabulario de las dos palabras contradice, por lo tanto, la idea que Solichón escogiera para su obra palabras poco conocidas, y aparece todavía más incongruo el hecho de que, aunque la entrada vaya encabezada por tamiz, en el tratado el autor le prefiriera cedazo: para encontrar una respuesta, podemos solo suponer que cedazo fuera el término más usado en la cocina del restaurante Lhardy.

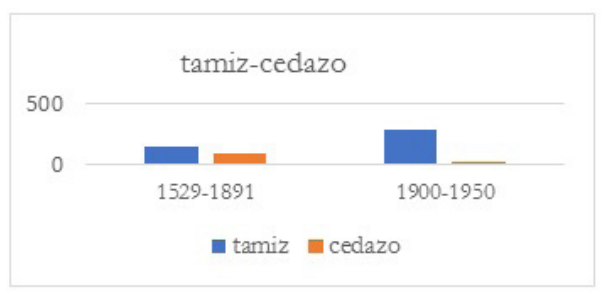

Figura 2. Frecuencia de uso de tamizy cedaro, siglos XVI-XX. 
A la idea de que el repertorio léxico en cuestión naciera de la necesidad de explicar palabras poco conocidas parece oponerse también el hecho de que, entre los sustantivos, no solo tami y cedaro, sino tampoco cocimiento, estameña y perol son formaciones neológicas, ya que se utilizan en gastronomía desde los siglos XVI y XVII. Asimismo, la frase que encabeza la entrada pinceles, instrumento al cual el autor se refiere apuntando que «Estos todo el mundo sabe lo que son» (Solichón 1900: 30), no confirma la hipótesis inicial. Puesto que la única atestación escrita de pinceles se encuentra en Muro (1891-1894), como en el caso de cedazo hay que buscar una motivación extralingüística a su presencia en nuestro vocabulario, o sea, el posible uso de la palabra pinceles entre los cocineros que utilizaban la técnica francesa del glaseado (glacè), usada en las preparaciones de carnes y postres.

\subsection{Verbos}

Todos los verbos reseñados en el glosario aparecen en el manual: de manera análoga a lo que notábamos en 3.1. para los sustantivos, no todas las entradas son palabras nuevas y, además, la frecuencia de algunas en el tratado es baja, como muestra la tabla 2. Están bien asentados en el idioma los verbos clarificar (CDH siglo XVI; Muro 1892); escalfar (CDH siglo XVII; Muro 1892); mechar (CDH siglo XVII; Muro 1892; Praussols 1900); sazonar (Muro 1892; Praussols 1900; CDH); tornear $(C D H)$.

\begin{tabular}{lll} 
Verbos & Ocurrencias & Formas neológicas \\
\hline sazonar & & \\
liar & 87 & $*$ \\
trabar & 16 & $*$ \\
salsear & 29 & $*$ \\
blanquear & 24 & \\
tornear & 16 & \\
clarificar & 12 & \\
escalfar & 7 & \\
mechar & 6 & $*$ \\
recortar & 6 & $*$ \\
gratinar & 6 & $*$ \\
brasear & 5 & $*$ \\
cincelar & 5 & $*$ \\
emplatar & 2 &
\end{tabular}

Tabla 2. Los sustantivos y su frecuencia de uso en el tratado 
Como decíamos, una de las entradas está compuesta por liar y trabar separados por una coma, para indicar la analogía de significado entre los dos verbos. En efecto, ambos aparecen juntos en la receta de las Almejas a la marinera, como muestra el siguiente contexto: «Cuando hierva se trabará o liará la salsa con un buen trozo de manteca amasada con un poco de harina» (Solichón 1900: 224). Trabar es un verbo asentado en castellano desde el siglo XVI y aparece en Autoridades (RAE 1739) con la definición «vale assimismo espessar, ò dar mayor consistencia á lo liquido» (s. v.); en cambio, liar no se registra en los diccionarios de referencia ni en el CDH con el significado de 'amasar' y, por lo tanto, hasta ahora el «Vocabulario» de Solichón representa su primera atestación. Sin embargo, en la microestructura el autor no habla de un verbo, sino de un sustantivo, ausente en el repertorio léxico estudiado; la definición, que explica detalladamente varios tipos de ligazones como el beurre mamé, se refiere a la forma neológica: «Liar, trabar. - Es la traducción de la palabra francesa liaison, que es la que se emplea generalmente en las cocinas» (Solichón 1900: 28). El verbo liar, menos frecuente de trabar en el tratado, es interpretable como una ampliación de significado del castellano liar, «atar y asegurar los fardos y cargas con lías» (RAE 1899), o sea, 'unir', inducida por influjo del galicismo lier, así descrito en el Trésor de la Langue Française: «ART CULIN. Lier une préparation. La rendre consistante et homogène en faisant une liaison». El interés de esta entrada radica en el hecho de que documenta el momento en que una formación de nuevo cuño compite con una palabra ya existente; sin embargo, la expresión liar una salsa es un fenómeno efímero, puesto que ya a partir de un tratado de cocina anónimo publicado en los años veinte del siglo XIX (1822b) se encuentran muestras de empleo del verbo ligar, que se irá imponiendo sobre trabar: ${ }^{11}$ «y en seguida se pican bien finas, se echan en la salsa y se hacen ligar al fuego» (1822b: 5).

Solichón describe cincelar como «cortar de manera tan fina que parece picado» (s. v.) y señala: «esta palabra no se emplea mucho en cocina, se dice generalmente cortar en forma de juliana - en francés se dice ciselens (s. v.). Cincelar procede del ámbito de la escultura como ciseler, y podría ser un calco efímero del segundo; asimismo, también en forma de juliana es un galicismo, ya que traduce la locución en julienne, cuyo éxito está bien documentado en el $C D H$, con una frecuencia normalizada de 122,08 casos por millón; la expresión se observa por primera vez en el ya mencionado tratado anónimo (1822b). La presencia como entrada de un francesismo poco conocido, explicado en la definición mediante una expresión de uso corriente, se puede atribuir a la intención del autor de ofrecer al destinatario una terminología al día, posiblemente la de las cocinas de restaurantes elegantes como Lhardy y del grupo selecto de cocineros de que forma parte, como destacan las palabras del prologuista de la obra: «Adolfo Solichón es de sobra conocido entre la gente de chaqueta blanca» (Capella 1900: 12). Brasear, gratinar y salsear, formados a partir de braiser, gratiner y saucer, son también galicismos nacidos a finales del siglo XIX, cuya primera documentación se encuentra en Muro (1891-1894).

11 La búsqueda en el subcorpus Gastronomía y cocina del CDH documenta que, a partir del siglo XIX hasta nuestros días, ligar es la forma más usada en España y en Hispanoamérica, con una frecuencia normalizada de 183,88 casos por millón, mientras que la de trabar es de 30,71 casos por millón. 
No son galicismos, en cambio, los verbos blanquear, documentado antes de El arte culinario solo en las obras de Muro (1891-1894; 1892), el neologismo de origen incierto emplatar -incluido en el «Vocabulario», pero ausente en el tratado- - y recortar, en el significado de «quitar á un pedazo de carne el sebo y pieles que la cubren» (Solichón 1900: s. v.).

\subsection{Lexías compuestas}

Solichón incluye en su «Vocabulario» las lexías compuestas que se muestran en la tabla 3: también en el caso de esta parcela léxica, algunas no se encuentran en el texto o sus ocurrencias son muy bajas.

\begin{tabular}{lcc|}
\hline Lexías compuestas & Ocurrencias & Formas neológicas \\
\hline plato de saltear & 84 & $*$ \\
manojo de hierbas aromáticas & 21 & $*$ \\
cazo de cobre & 10 & $*$ \\
fondos de cocina & 1 & $*$ \\
cacerola rusa & 0 &
\end{tabular}

Aunque Manojo de hierbas aromáticas se documente en los libros de cocina desde el siglo XVII, como demuestra una búsqueda realizada a través de Google Libros, al incluirlo en su recopilación Solichón subraya su escaso uso, dado que, según él, «En cocina se llama generalmente bouquet-garni, tomando su nombre del francés» (1900: s. v.). En este caso, la voz española es una manera de atraer la atención sobre el término francés, más apropiado en una cocina elegante. Cazo de cobre en el significado de «cacerola de cobre á bordes altos sin estañar su interior» (s. v.) se documenta a partir del siglo XVIII (cf. Google Libros).

Proceden directamente del francés los términos siguientes: cacerola rusa — traducción del término francés casserole russe — , cuyo primer testimonio es precisamente nuestro vocabulario; plato de saltear, del francés plat à sauter, y fondos de cocina, de fonds de cuisine, que no se encuentran en el CDH ni en los diccionarios consultados, pero la búsqueda en Google Libros muestra su uso en varios textos de cocina de la mitad del siglo XIX.

\section{Conclusiones}

Del análisis del «Vocabulario de varios términos culinarios» y de la relación entre este y el texto del tratado de Solichón se infieren, como hemos visto, varias incongruencias. Por ejemplo, algunas de las palabras incluidas en el glosario, en realidad, no se emplean nunca en el texto del tratado. Sin embargo, las incongruencias aludidas no deben llevarnos a desestimar el interés del glosario redactado por nuestro cocinero. Todo lo contrario. 
Obviamente, Solichón no es lingüista, sino — como se desprende de nuestro análisis — un especialista de su oficio que se da cuenta de la importancia primordial que tiene la terminología para quien se acerque al campo culinario. De ahí que en su glosario incluya solo - come dice él mismo- una «ligera explicación» (1900: 21) de las voces, como cabe esperar de una obra que, ya desde su cubierta, se presenta como «tratado práctico».

La caracterización del léxico del «Vocabulario de varios términos culinarios» podrá delinearse de manera más contrastada a la luz del trabajo futuro que queremos dedicar al análisis de su microestructura y a la relación entre el léxico culinario propuesto por nuestro autor en su recopilación y el empleado en materiales auténticos del ámbito de la gastronomía de finales del siglo XIX y comienzos del XX.

De todos modos, de las presentes páginas ya se pueden desprender algunos aspectos de cierta envergadura. Los frecuentes galicismos — de los que hemos visto varios ejemplos- son, sin lugar a dudas, el resultado de una acusada influencia lingüística, la del francés y de su cultura gastronómica, que a lo largo de los siglos XVIII y XIX se difunde en muchísimos ámbitos. Al mismo tiempo, Solichón incorpora, como hemos observado, bastantes formaciones neológicas. Incluso algunas que, como hemos documentado en los casos de varillas, boquillas, tambor, manga, cuerna y pasa-caldo, no se encuentran con el significado presentado por Solichón ni en el CDH ni en los diccionarios especializados consultados.

Todo ello nos recuerda, una vez más, que poner el foco en los glosarios escondidos permite enriquecer el conocimiento de la terminología de las lenguas de especialidad del pasado y supone un avance para la lexicografía histórica. 


\section{Bibliografía}

Anónimo (1929 [1529]) Libro de guisados de Ruperto de Nola, ed. de Dionisio Pérez, Madrid, Compañía Iberoamericana de Publicaciones.

Anónimo (1822a) El repostero famoso, amigo de los golosos, Madrid, Imprenta de Eusebio Álvarez.

Anónimo (1822b) Apéndice a la madre de las obras, o sea tomo III de la cocinera económica, Madrid, Imprenta de Eusebio Álvarez.

Biblioteca Nacional de España, <http://catalogo.bne.es/uhtbin/webcat> [última consulta: 19/10/2021].

Biblioteca Nacional de España, Hemeroteca digital [en línea], <http://hemerotecadigital.bne.es/ index.vm> [última consulta: 27/09/2021].

Capella, F. (1900) «Á 'Guisa’ de Prólogo», en Solichón, A., El arte culinario. Tratado práctico y completo de cocina, pastelería y repostería según la escuela moderna francesa y española, Madrid, Romo y Füssel, pp. 9-12.

Corominas, J. / Pascual, J. A. (1980-1991) Diccionario crítico etimológico castellano e hispánico, Madrid, Gredos, 6 vols.

Díez de Revenga Torres, P. (2008) «El léxico de la minería a través de un diccionario inédito del siglo XVIII», en Azorín, D. (dir.), El diccionario como puente entre las lenguas y culturas del mundo. Actas del II Congreso Internacional de Lexicografía Histórica, Alicante, Biblioteca Virtual Miguel de Cervantes, pp. 655-662.

Google Libros, <https://books.google.es/> [última consulta: 19/10/2021].

Gutiérrez Rodilla, B. / García Jáuregui, C. (2012) «Repertorios lexicográficos ‘escondidos’ del Renacimiento: el glosario médico de Bartolomé Hidalgo de Agüero», en Rio-Torto, G. (ed.), Léxico de la Ciencia: tradición y modernidad, München, LINCOM, pp. 132-140.

Martínez Llopis, Manuel M. (1998) Historia de la gastronomía española, Barcelona, Altaya [1.a ed. Madrid, Alianza, 1989].

Ministerio de Cultura y Deporte, Biblioteca virtual de prensa histórica [en línea] <https:// prensahistorica.mcu.es/es/inicio/inicio.do > [última consulta: 27/09/2021].

Muro, Á. (1892) Diccionario General de Cocina, Madrid, José María Faquineto Editor.

Muro, Á. (1891-1894) El Practicón. Tratado completo de cocina al alcance de todosy aprovechamiento de sobras, Madrid, Librería de Miguel Guijarro.

Pablo Núñez, L. / De Beni, M. (2019) «El Manual del cajista $(1845,1861)$ de José María Palacios y su vocabulario de voces de la imprenta», Revista de Historia de la Lengua Española, 14, pp. 3-27.

Pinilla, J. / Lépinette, B. (2012) «Análisis de un léxico escondido. El Diccionario añadido por M. J. Suárez Núñez a su traducción del Art du cirier (1762) de H. L. Duhamel du Monceau», en RioTorto, G. (ed.), Léxico de la Ciencia: tradición y modernidad, München, LINCOM, pp. 192-202. 
Elena Carpi \& Matteo De Beni. El glosario escondido en El arte culinario (1900) de Adolfo Solichón

Praussols, J. de (1900) Pequeño Diccionario Ilustrado de los términos usuales en la cocina, Madrid, Hernando y Compañía, Libreros Editores.

Real Academia Española, Corpus del Nuevo diccionario bistórico (CDH) [en línea], <http://web.frl.es/ CNDHE> [última consulta: 05/10/2021].

Real Academia Española, Nuevo tesoro lexicográfico de la lengua española (NTLLE) [en línea], <https:/ / apps.rae.es/ntlle/SrvltGUISalirNtlle> [última consulta: 05/10/2021].

Solichón, A. (1900) El arte culinario. Tratado práctico y completo de cocina, pastelería y repostería según la escuela moderna francesa y española, Madrid, Romo y Füssel.

Torres Martínez, M. (2018) «Léxico culinario decimonónico: el glosario escondido incluido en El Practicón. Tratado completo de cocina (1894) de Ángel Muro», Diálogo de la lengua, 10, pp. 56-75.

Trésor de la Langue Française informatisé, [en línea], <http:/ / atilf.atilf.fr> [última consulta: 05/10/2021].

Un gastrónomo jubilado (1869) La gran economía de las familias. Arte de arreglar y componer lo sobrante de las comidas de un día para otro [...], Madrid, Imprenta de F. López Vizcaíno. 